\title{
Análisis de sistemas de riego por gravedad y goteo subsuperficial basada en una encuesta de muestra de conveniencia en el valle de Mexicali.
}

\section{Analysis of gravity and subsurface drainage irrigation systems based on a convenience sample survey in the Mexicali valley.}

B. BRINGAS-BURGOS, *I. MENDOZA-MUÑOZ, C. NAVARRO-GONZÁLEZ,

A. GONZÁLEZ- ÁNGELES Y G. JACOBO-GALICIA

\author{
Universidad Autónoma de Baja California, Facultad de Ingeniería Mexicali, \\ Blvd. Benito Juárez S/N, C.P. 21280, \\ Mexicali, Baja California, México \\ *ismael.mendoza@uabc.edu.mx, \\ Tel.: +52-686-566-4270
}

\section{RESUMEN}

La producción agrícola en el valle de Mexicali ha tenido una historia llena de contrastes. Aunque la actividad agrícola se encuentra en una recesión de la que apenas puede recuperarse, las prácticas agrícolas continúan sin cambios significativos, con la conservación y la gestión sostenible de los recursos como una prioridad. El siguiente estudio busca evaluar el perfil productivo tradicional del cultivo de alfalfa utilizando el sistema de riego por gravedad y lo compara con un sistema de riego por goteo subterráneo. El Marco de Evaluación de Sistemas mediante Indicadores de Sustentabilidad (MESMIS) se utilizó para definir el sistema que ofrece mejores condiciones en términos sustentables para la realidad actual del Valle de Mexicali. Los resultados proponen un escenario favorable para el sistema de riego por goteo en ocho de los 10 indicadores propuestos y analizados. En términos de sustentabilidad, el sistema de riego por goteo mostró superioridad en los atributos de productividad, equidad, resiliencia y adaptabilidad; mientras que el sistema de riego por gravedad presentó predominio en autogestión.

Palabras Clave: Riego por goteo, riego por gravedad, agricultura, sustentabilidad, MESMIS. 


\section{ABSTRACT}

Agricultural production in the Mexicali Valley has had a history full of contrasts. Even though agricultural activity is in a recession from which it can hardly recover, agricultural practices continue without significant changes, with conservation and sustainable management of resources as a priority. The current study seeks to evaluate the traditional productive profile of alfalfa farming using a gravity irrigation system and compares it with a subsurface drip irrigation system. The Systems Assessment Framework through Sustainability Indicators was used to define the system that offers better conditions in terms of sustainability for the present reality of the Mexicali Valley. The results propose a favorable scenario for the drip irrigation system in eight of the 10 indicators proposed and analyzed. In terms of sustainability, the drip irrigation system showed to be superior in the attributes of productivity, equality, resilience, and adaptability, while the gravity irrigation system showed predominance in self-management.

Keywords: Drip irrigation, gravity irrigation, agriculture, sustainability, MESMIS.

\section{INTRODUCCIÓN}

Con el final de la Segunda Guerra Mundial, la política global se priorizaba en aumentar la productividad a través de la industrialización y altos niveles de insumos (energía, fertilizantes y pesticidas). Aun cuando esta estrategia ofrece inmediatamente rendimientos, sus resultados son cuestionados por los efectos ambientales negativos (contaminación de las aguas subterráneas, erosión del suelo, pérdida de biodiversidad, etc.). Actualmente, la agricultura hace frente a un número importante de retos (volatilidad del mercado, escasez de recursos, aumento de la demanda de materias primas, etc.), los cuales amenazan el futuro de los sistemas de producción agrícola, los ecosistemas y los beneficios que entrega a la sociedad (Rupérez-Moreno et al., 2017).

Sin embargo, la agricultura ha recibido poca atención en muchos países en los últimos años, mientras que en otros se han establecido medidas proteccionistas que han refugiado a este sector por medio de una necesaria reestructuración como respuesta a estos retos (Vörösmarty, 2010). Estos últimos, tienen claro que el estado del medio ambiente y su correcta administración es una de las condiciones iniciales para el desarrollo sostenible de cualquier país, asegurándose que las medidas tomadas no pongan en peligro el recurso global y las bases ambientales del mismo (Singh, 2016).

Los sistemas de producción agrícolas presentan una serie de inconvenientes importantes debido a que la agricultura convencional no es comúnmente relacionada con la conservación y la gestión sostenible de recursos. Asimismo, estos sistemas deben ser sostenibles en términos sociales, económicos y ambientales, con el fin de atender a las necesidades de la sociedad (Singh, 2016).

Una serie de acontecimientos moldearon la agricultura del Valle de Mexicali desde los primeros años hasta la actualidad. Sin embargo, el periodo de los años sesenta sobresale debido a que la producción agrícola fue severamente golpeada 
por diversos factores (nuevos competidores a nivel mundial, problemas de salinidad en las tierras, aparición de nueva plaga con resistencia, retiro de apoyos gubernamentales e inversión extranjera, etc.), entrando a una crisis sin retorno. Es importante señalar que aun cuando la producción de cultivos agrícolas han presentado cambios significativos en el modelo de producción y en las condiciones del entorno, las prácticas agrícolas no han cambiado mucho (Alvarado, 2007; Moreno Mena \& López Limón, 2005).

El agua es un elemento es esencial para el desarrollo de las distintas actividades del ser humano como: la industria, el hogar, la ganadería, el turismo, la piscicultura, para beber, lavar la ropa, cocinar, y, predominantemente, en la producción de alimentos agrícolas y pecuarios (Broa-Rojas et al., 2013). Con respecto a la agricultura en México, ésta actividad emplea por año aproximadamente un $77 \%$ del total de agua disponible en el país (Chávez et al., 2010).

A finales del 2009, el estado de Baja California utilizaba anualmente 3,610 millones de metros cúbicos de agua, siendo el principal usuario el sector agrícola con $80 \%$ del volumen concesionado, seguido del abastecimiento público-urbano y doméstico con $12 \%$, el uso para termoeléctricas con el $5 \%$, el uso industrial con $2 \%$ y otros usos con el $1 \%$. De los cinco municipios que conforman Baja California, es Mexicali quien consume el $95 \%$ del agua superficial y el 52\% del agua subterránea del estado (CONAGUA, 2012).

En el Valle de Mexicali a nivel parcelario, el riego por gravedad logra una eficiencia en la aplicación de agua de alrededor del
$71 \%$ pero, al considerar la pérdida en los canales resulta en una eficiencia total del $56 \%$ lo cual refleja que aproximadamente la mitad del agua que proviene del Río Colorado es aprovechado por el cultivo (Martínez Camacho, 2010).

En relación a la producción de cultivo, se cuenta con series estadísticas de la Oficina Estatal de Información para el Desarrollo Rural Sustentable (OEIDRUS) de Baja California en el 2013, donde se destacan al trigo, la alfalfa y algodón como los cultivos con más hectáreas sembradas en el Valle de Mexicali, sin embargo, de estos cultivos el mayor consumidor potencial de agua es la alfalfa debido a sus altas necesidades hídricas al tomar en cuenta su larga temporada de crecimiento (OEIDRUS BC, n.d.).

Aun cuando en México se cuenta con censos agropecuarios llevados a cabo por INEGI, el manejo a nivel parcelario requiere información clara y específica sobre las dimensiones y características reales que enfrenta la producción agrícola del Valle de Mexicali. El desconocimiento de lo anterior, contribuye a obstaculizar el diseño e implementación de estrategias y políticas adecuadas para potenciar la sustentabilidad de la producción, siendo importante que empresarios, gobierno, productores y académicos enfoquen sus destrezas en vías de fomentar un cambio de paradigma en la sociedad en la búsqueda de prácticas de producción agrícola sostenibles y generando información que sea de utilidad para el análisis y diagnóstico de comunidades rurales en sus diferentes escalas (Vélez Vargas, 2004).

En este trabajo se aborda una evaluación del perfil productivo tradicional de cultivo de alfalfa empleando el sistema de riego por gravedad y una propuesta utilizando el sistema de riego 
Análisis de sistemas de riego por gravedad y goteo subsuperficial basada en una encuesta de muestra de conveniencia en el valle de Mexicali B. Bringas-Burgos, I. Mendoza-Muñoz, C. Navarro-González, A. González-Ángeles y G. Jacobo-Galicia

- VÍNCULOS-ESPE (2020) VOL.5, No.3: 13 - 32

por goteo subsuperficial a través del Marco de Evaluación de Sistemas mediante Indicadores de Sustentabilidad (MESMIS), proporcionando una base para determinar cuál sistema ofrece las condiciones más apropiadas en relación con las características y dimensiones presentes en el Valle de Mexicali.

\section{MATERIALES Y MÉTODOS}

Para la realización de este estudio, se ha optado por la aplicación del marco de evaluación MESMIS ya que está en función de un sistema de referencia con un sistema alternativo (sistemas de riego por gravedad y por goteo subsuperficial). Lo anterior propone una evaluación de comparación de sustentabilidad, es decir, una evaluación que conlleva a declaraciones como "este sistema es más (o menos) sustentable que este otro" precisamente porque

Tabla 1. Metodología de evaluación para sistemas productivos agrícolas en el Valle de Mexicali.

\begin{tabular}{|c|c|c|c|}
\hline & Paso mełodológico & Requerimientos & Acciones \\
\hline 1 & $\begin{array}{l}\text { Determinar objeto de } \\
\text { evaluación }\end{array}$ & Visita a la unidad productiva tradicional. & Revisión de literatura \\
\hline 2 & Caracterización & Aplicación de encuesta exploratoria & $\begin{array}{l}\text { Elaboración y aplicación de entrevistas a agricultores cuyo contenido } \\
\text { evidencie las entradas y salidas del sistema, así como la descripción } \\
\text { del entorno ambiental y socioeconómico del área de estudio }\end{array}$ \\
\hline 3 & $\begin{array}{l}\text { Definición de puntos } \\
\text { críticos }\end{array}$ & $\begin{array}{l}\text { Definición de problemas o áreas } \\
\text { "insostenibles" del sistema }\end{array}$ & $\begin{array}{l}\text { Aplicación de entrevistas a agricultores, obreros, administradores y } \\
\text { actores influenciados por el sistema }\end{array}$ \\
\hline 4 & Selección de indicadores & $\begin{array}{l}\text { Determinar indicadores a través de puntos } \\
\text { críticos }\end{array}$ & $\begin{array}{l}\text { Determinar indicadores factibles de medición (fácil de medir e } \\
\text { interpretar, coherencia entre el alcance de indicadores, deben } \\
\text { proporcionar información relevante, factibles de futuras mediciones) }\end{array}$ \\
\hline 5 & Medición de indicadores & $\begin{array}{l}\text { Análisis de información obtenida en } \\
\text { encuestas y muestreos de campo }\end{array}$ & Aplicación de encuestas, análisis de laboratorio, revisión de literatura \\
\hline 6 & Integración de resultados & $\begin{array}{l}\text { Selección de umbrales o valores de } \\
\text { referencia para indicadores. }\end{array}$ & $\begin{array}{l}\text { Revisión de literatura, comparaciones pareadas, porcentaje de la } \\
\text { muestra }\end{array}$ \\
\hline 7 & $\begin{array}{l}\text { Conclusiones y } \\
\text { recomendaciones }\end{array}$ & $\begin{array}{l}\text { Evaluación de los atributos de } \\
\text { sustentabilidad y propuesta de estrategias } \\
\text { para medir el perfil sustentable }\end{array}$ & Revisión de literatura, opinión de expertos locales \\
\hline
\end{tabular}


hasta ahora, determinar la sustentabilidad en términos absolutos no es posible. El sistema de referencia representa los patrones técnicos y sociales más comunes de la región donde se realiza el estudio. El sistema de manejo alternativo incorpora cualquier innovación tecnológica o social. MESMIS es definida a partir de cinco atributos generales de los agro-ecosistemas o sistemas de manejo: 1. productividad; 2. estabilidad, confiabilidad y resiliencia; 3. adaptabilidad; 4. equidad y 5. autogestión (Astier et al., 2008; Neri-Ramírez et al., 2013).

Para la realización de este estudio se hizo uso de una combinación de enfoques de acuerdo con los sistemas a estudiar, los cuales se muestran en la Tabla 1 como los pasos metodológicos, requerimientos y acciones tomadas para finalmente concluir que perfil es más favorable para la producción agrícola el Valle de Mexicali en términos sustentables.

\section{RESULTADOS}

\subsection{Objeto de Evaluación}

Los datos fueron obtenidos en fechas comprendidas entre septiembre de 2015 y julio de 2016 , en donde las mediciones se elaboraron de forma aleatoria, a través de recorridos en del Valle de Mexicali con ayuda de colaboradores de la región en distintos puntos, logrando localizar diversos predios con el cultivo a estudiar y en donde los agricultores tuvieran la disponibilidad de participar. En la Figura 1 se presenta la ubicación de los puntos de muestreo, en donde los primeros 11 representan cultivos que emplean sistema de riego por gravedad y el marcado con el número 12 presenta un cultivo de alfalfa con el sistema de riego por goteo subsuperficial. Durante este periodo, se realizaron entrevistas semiestructuradas a los productores y operadores de maquinaria, así como pláticas informales, entrevistas con autoridades y funcionarios de gobierno, se consultaron diversas bases de datos estadísticos (OEIDRUS BC, INEGI, INIFAP), además de recorridos por los campos y canales.

Figura 1. Puntos de muestreo en el Valle de Mexicali.

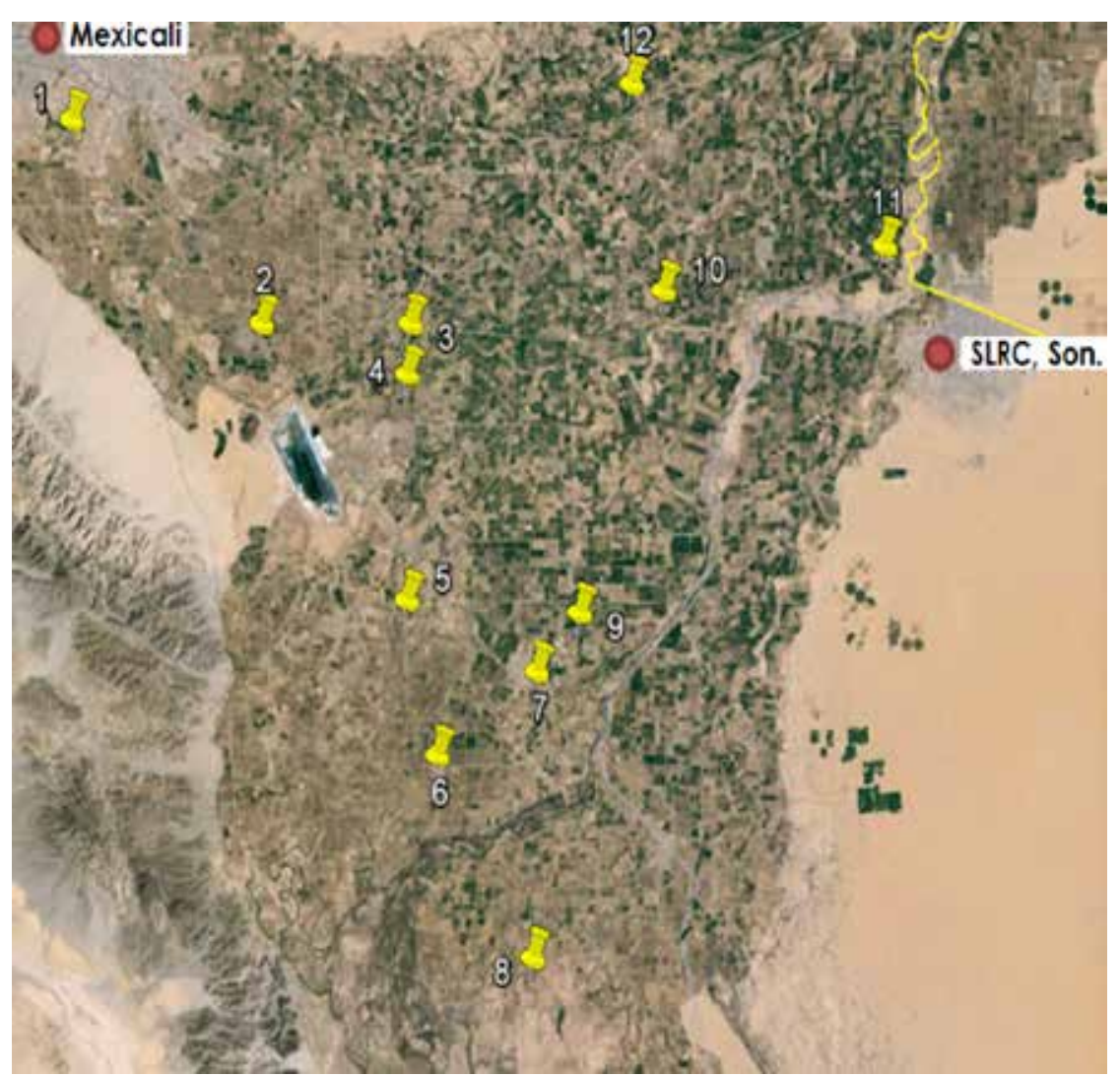


Análisis de sistemas de riego por gravedad y goteo subsuperficial basada en una encuesta de muestra de conveniencia en el valle de Mexicali B. Bringas-Burgos, I. Mendoza-Muñoz, C. Navarro-González, A. González-Ángeles y G. Jacobo-Galicia

- VÍNCULOS-ESPE (2020) VOL.5, No.3: 13 - 32

\subsection{Caracterización}

En base a la revisión de literatura, se diseñó un cuestionario piloto el cual cuenta con 37 reactivos y engloba 15 áreas temáticas. Una vez analizada la información recopilada por éste primer cuestionario, se propone un segundo el cual requiere la participación de obreros y operadores de maquinaria. Este segundo cuestionario está formado por 26 reactivos y comprende 9 áreas

temáticas. El objetivo de los cuestionarios es contar con una herramienta que permita caracterizar ambos perfiles de estudio desde los enfoques socioeconómicos, agrícolas y del mismo proceso productivo, para posteriormente definir los puntos críticos del estudio. La Tabla 2 detalla las áreas temáticas de cada cuestionario, así como el número de reactivos asignados a cada uno.

Tabla 2. Estructura de los cuestionarios empleados para la caracterización de los sistemas de riego.

\begin{tabular}{|c|c|c|c|}
\hline \multicolumn{2}{|l|}{ Cuestionario \# 1 (piloto) } & \multicolumn{2}{|l|}{ Cuestionario \#2 } \\
\hline Área temática & No. Reactivos & Área temática & No. Reactivos \\
\hline Información general del productor y parcela & 9 & Tenencia de la tierra & 2 \\
\hline Tipo de semilla & 3 & Percepción del sistema & 5 \\
\hline Sistema de siembra & 1 & Uso de combustible & 1 \\
\hline Labores mecanizadas y costo de labores & 1 & Mano de obra & 4 \\
\hline Fecha de preparación de suelo y siembra & 3 & Organización & 5 \\
\hline Nutrición & 3 & Comercialización & 4 \\
\hline Principales problemas de la producción de alfalfa & 1 & Prospectiva del uso de riego tecnificado & 2 \\
\hline Uso de agua & 3 & Uso de fertilizante orgánico & 2 \\
\hline Problemas de seguridad y almacenaje & 3 & Uso de fertilizante orgánico83 & 2 \\
\hline Rendimiento & 2 & Capacitación & 1 \\
\hline Infraestructura y equipo & 2 & & \\
\hline Capacitación & 2 & & \\
\hline Plagas y enfermedades & 2 & & \\
\hline Percepción de los sistemas de riego por goteo & 1 & & \\
\hline Destino de la producción & 1 & & \\
\hline
\end{tabular}




\subsubsection{Características socioeconómicas}

En la Figura 2 se exponen una serie de gráficas sobre las características socioeconómicas de los puntos de muestreo. Los resultados de ambos cuestionarios presentan una semejanza clara con la agricultura empresarial, tomando en cuenta factores como: uso de seguro agrícola, disponibilidad de maquinaria y equipo, existencia de institución normativa que organiza la repartición de recursos; así como características presentes en el entorno tales como: acceso a servicios públicos, vías de acceso y comunicaciones. Sin embargo, se conservan algunas similitudes de la agricultura campesina en cuanto a: mano de obra familiar, escasa división del trabajo, comercialización en mercados locales, manejo de pluricultivos, por mencionar algunos.

Figura 2. Características socioeconómicas de la muestra.

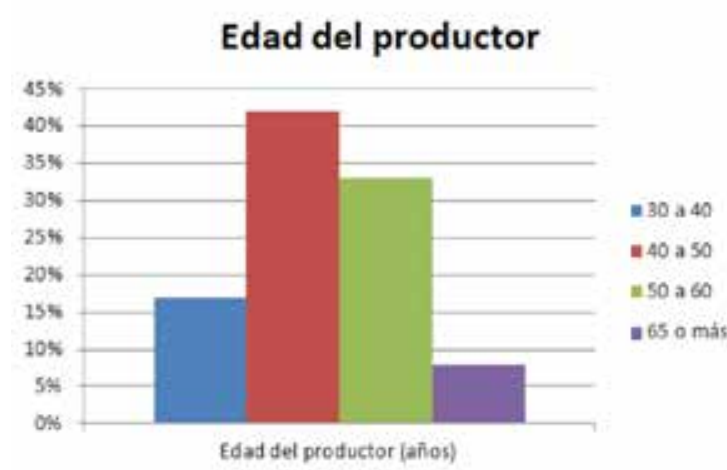

Victima de robo de equipo o herramienta

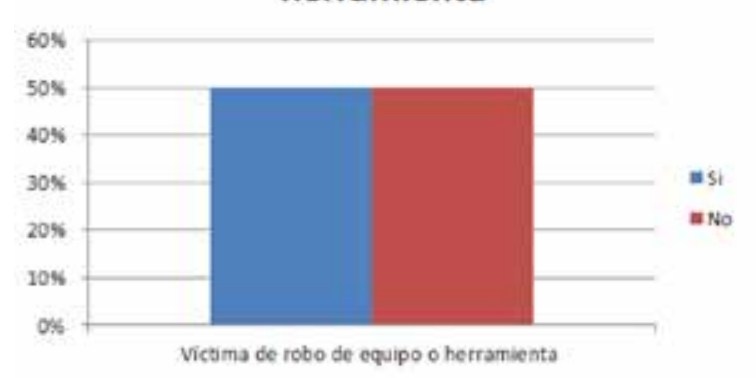

\section{Sexo del productor}

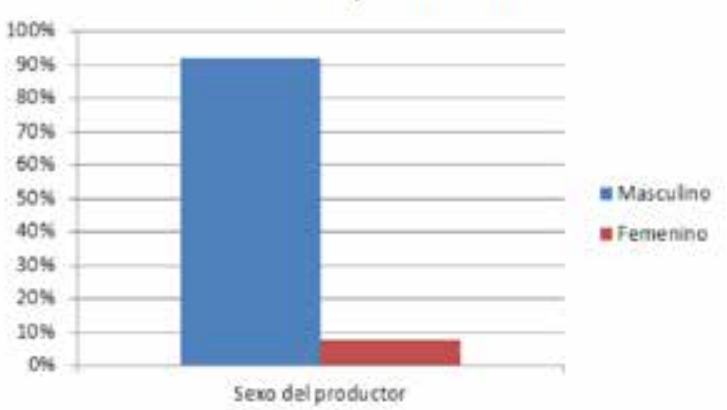

Tenencia de la tierra

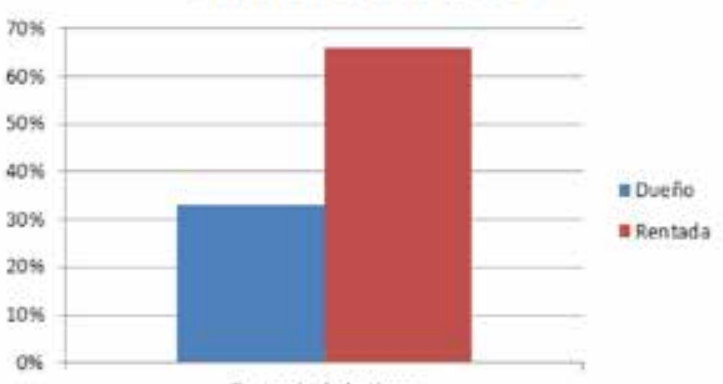

Tenencia de ta tiersa
Fuente de ingresos adicionales

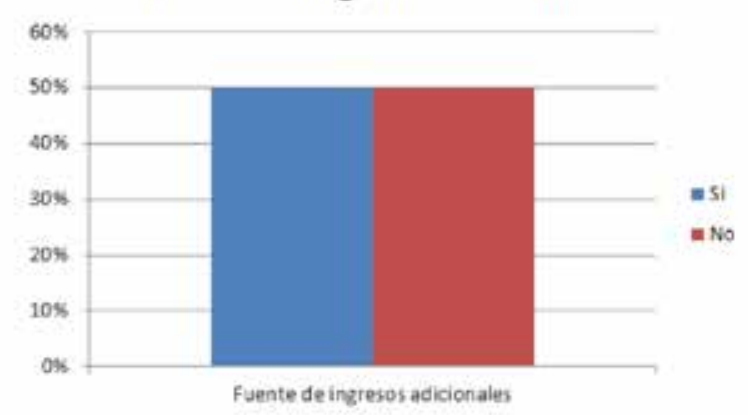

Tenencia de la maquinaría agricola

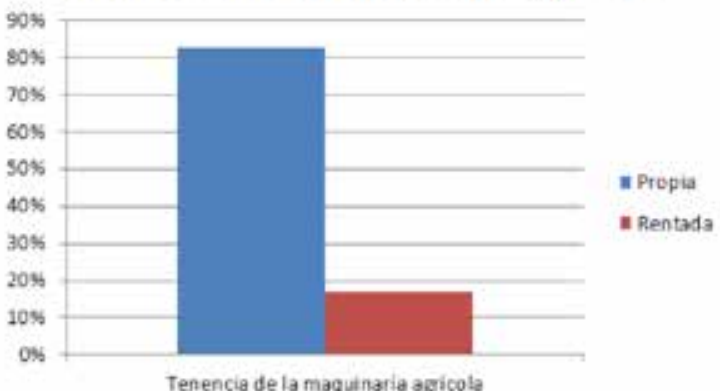


Figura 2. Características socioeconómicas de la muestra.

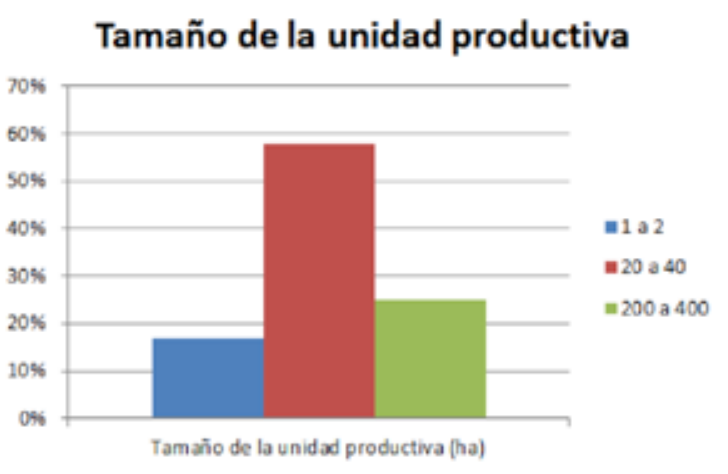

Uso del seguro agrícola

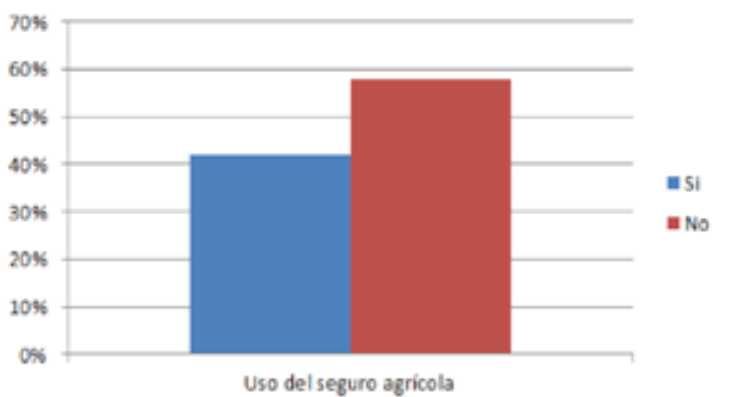

\section{Destino de producción}

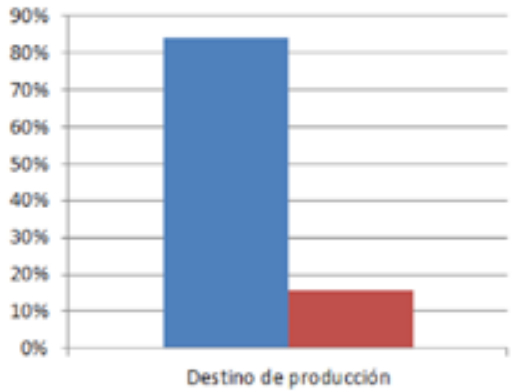

Participación en reuniones del módulo de riego

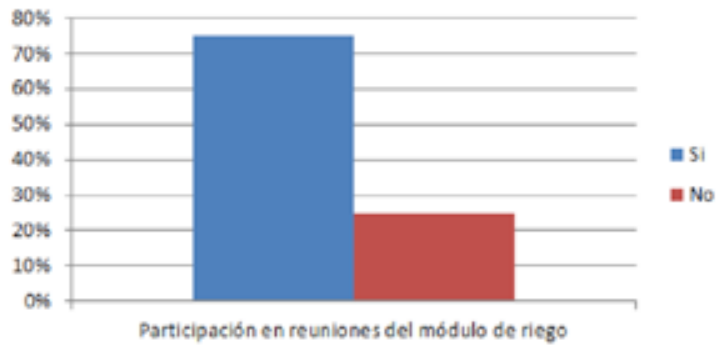

Venta becal 0 intermediarios
Número de compradores de alfalfa

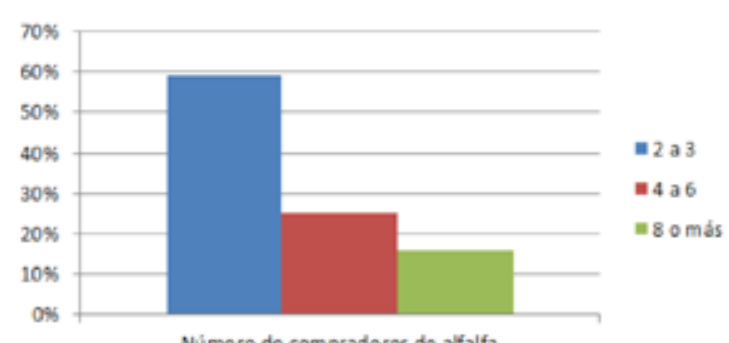

Wimero de compradores de affalfa

Salario diario de obrero (pesos)

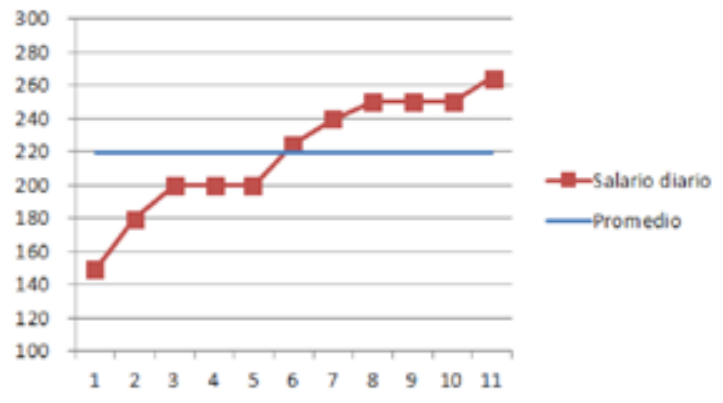

\subsubsection{Características agrícolas}

En la Figura 3 se agrupan los gráficos correspondientes a las características agrícolas de los puntos de muestreo. A grandes rasgos, el contexto agrícola puede definirse como: altamente mecanizado empleando tecnología moderna, producción orientada a mercados locales, venta a intermediarios y acceso a créditos como asistencia técnica. 
Figura 3. Características agrícolas de la muestra.

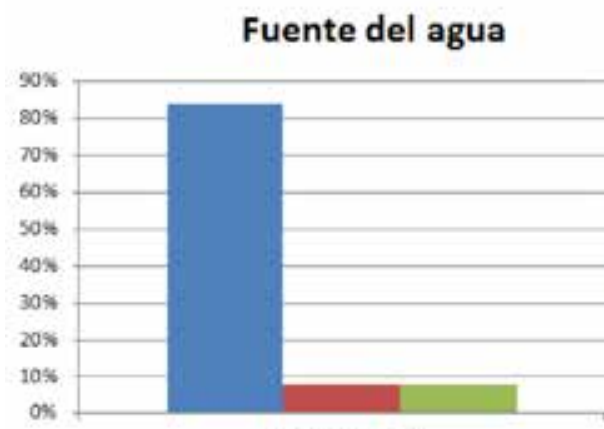

Fuente del agua

Método de control de plagas

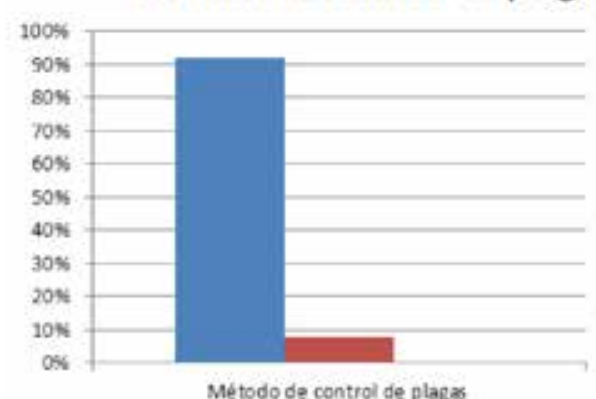

Uso de fertilizantes

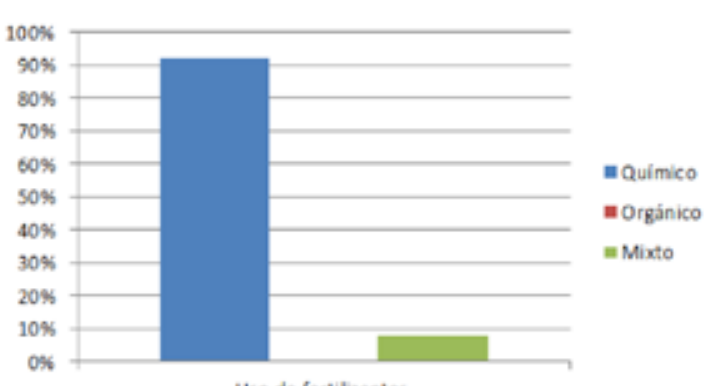

Uso de fertilizantes

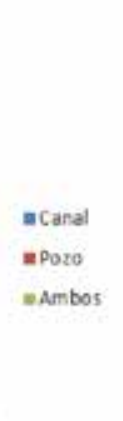

Quimica

misologico

NNinguna

Quimico

Orgánice

\section{Siembra de cultivo}

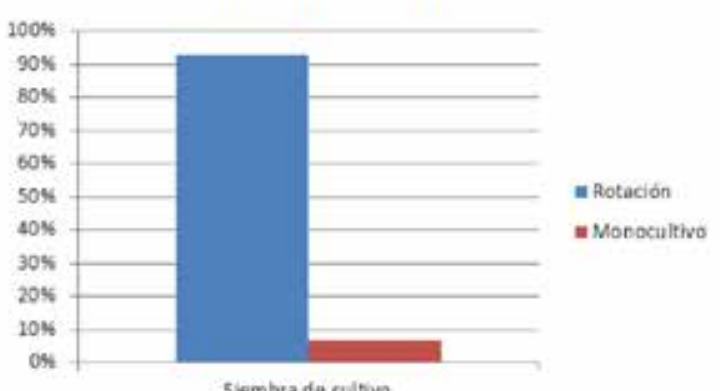

Siembra de culsvo

\section{Número de fumigaciones al año}

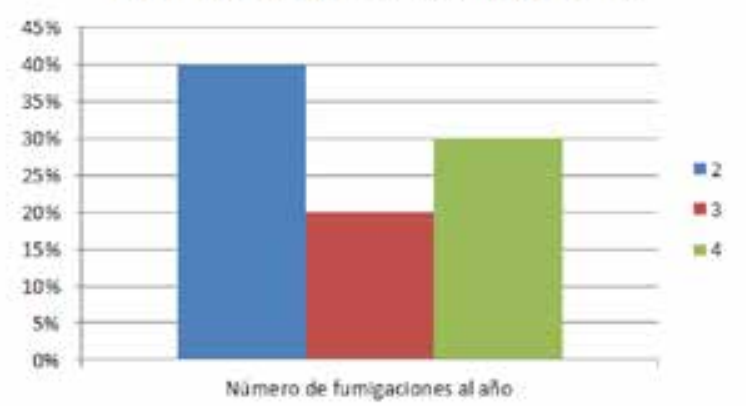

Impartición de capacitación agrícola

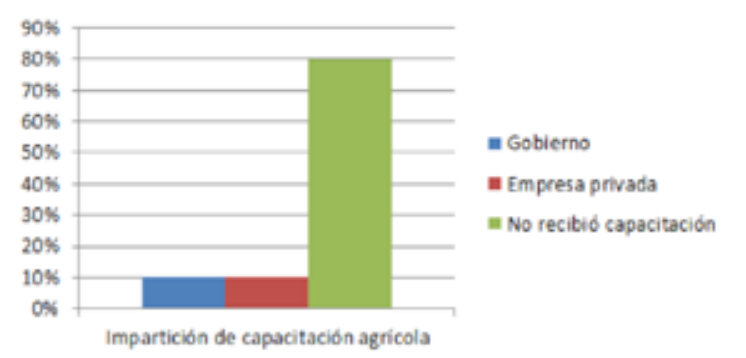

Método de siembra y cosecha

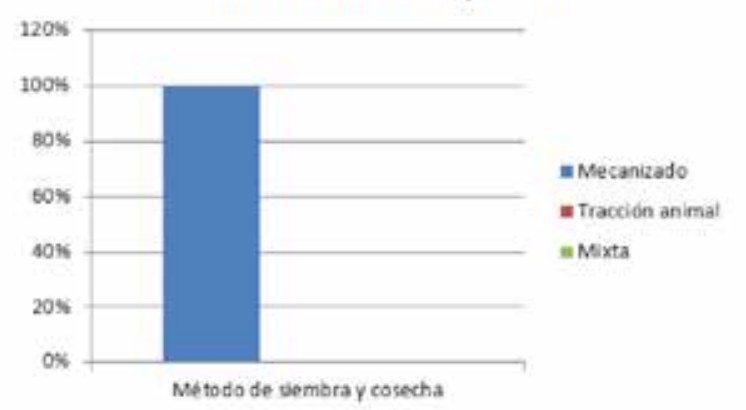

Análisis de suelo

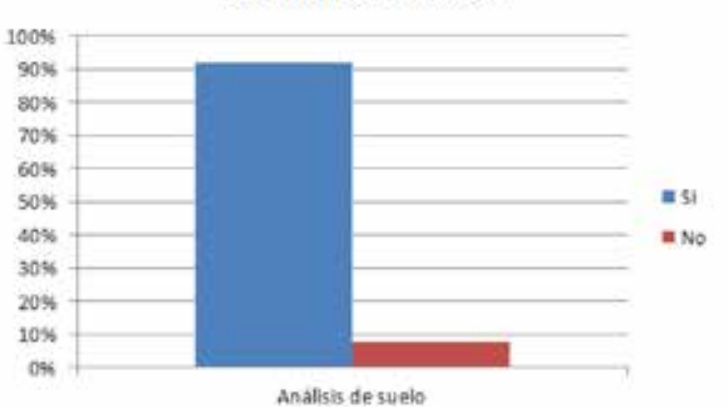

Registro de actividades de producción

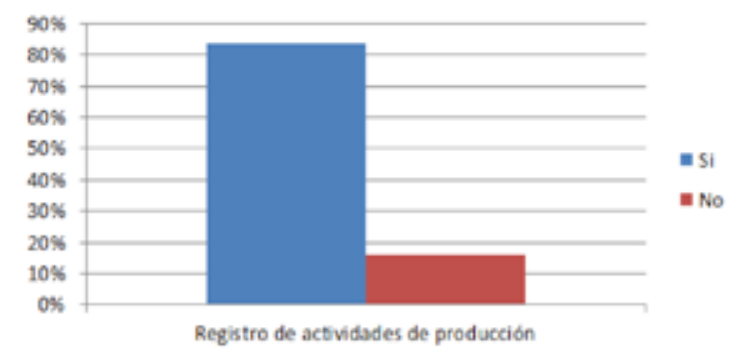


Análisis de sistemas de riego por gravedad y goteo subsuperficial basada en una encuesta de muestra de conveniencia en el valle de Mexicali B. Bringas-Burgos, I. Mendoza-Muñoz, C. Navarro-González, A. González-Ángeles y G. Jacobo-Galicia

- VÍNCULOS-ESPE (2020) VOL.5, No.3: 13 - 32

\subsubsection{Caracterización del proceso productivo}

\subsubsection{Proceso con sistema de riego por gravedad (referencia)}

La producción de alfalfa con riego por gravedad consiste en la introducción del flujo de agua en un borde del terreno para que el agua cubra el área gradualmente, delimitando el paso de agua a través de bordos (melgas). El ciclo productivo en el Valle de Mexicali comienza con la preparación de la tierra durante los meses de agosto a septiembre. Después se aplica fertilización en pre-siembra. A continuación, se procede con la siembra y posteriormente se aplica el riego de germinación con alrededor de $25 \mathrm{l} / \mathrm{s}$ por $24 \mathrm{~h}$ por hectárea. En el ciclo productivo se aplican alrededor de ocho a nueve riegos, utilizando 15 a $18 \mathrm{l} / \mathrm{s}$ por $24 \mathrm{~h}$ por hectárea. Dependiendo de la disponibilidad de agua y fertilizante, se consiguen entre cinco y siete cortes en el año, de los cuales se obtuvo un promedio normal en la muestra de 12.92 ton por hectárea de heno seco. El objetivo principal de la producción es la venta a intermediarios o consumidores finales. Para el saneamiento del cultivo se utilizan grandes cantidades de insecticidas y herbicidas, alrededor de 3 aplicaciones de herbicidas y plaguicidas al año, dependiendo de las necesidades. Referente a la fertilización el uso de abono orgánico es bajo, solo uno de los agricultores de la muestra utiliza abono de gallina (gallinaza) el resto de la muestra utilizó mejoradores de suelo. Debido a las necesidades hídricas de la alfalfa y la baja eficiencia de distribución de agua, todos los agricultores deben comprar mayores cantidades de agua para regar el cultivo. Después de cada corte se realizan las actividades de rastrillo, empaque y levante de pacas.

\subsubsection{Proceso con sistema de riego por goteo subsuperficial}

La muestra que emplea este sistema de riego cuenta con un terreno de 17 hectáreas. Su ciclo productivo comienza con la preparación de la tierra. Se lleva a cabo la siembra, se fertiliza en pre-siembra y posteriormente se aplican los riegos de germinación a través de un sistema de riego por aspersión, se aplican varios riegos para germinación y desarrollo inicial de la planta durante un mes aproximadamente, hasta que las raíces de la planta son suficientes para alcanzar la humedad provista por el sistema de riego por goteo subsuperficial. Sin embargo, en caso de no contar con un sistema de riego por aspersión, se puede utilizar un riego de germinación por rodado, para ello se requieren hacer las labores de bordeo y canalización antes de la siembra. Después de la germinación, el suministro de riego se realiza mediante el uso de una motobomba de combustión diésel con capacidad de $30 \mathrm{l} / \mathrm{s}$, empleando un reservorio para la aplicación oportuna del agua, ya que se requieren de múltiples riegos para aplicar la cantidad requerida por la planta, El caudal utilizado en un ciclo productivo está alrededor de $135 \mathrm{I} \mathrm{I/s} \mathrm{por}$ $24 \mathrm{~h}$ por hectárea. El sistema de riego por goteo requiere una supervisión constante de fugas, ya que la fauna local puede dañar la cinta y los accesorios del sistema. El primer corte que se lleva a cabo en los meses de enero y febrero no se considera significativo, ya que contiene una cantidad considerable de maleza emergida durante los riegos de germinación, la cual desaparecerá casi por completo para los siguientes cortes. Se obtienen alrededor de 11 cortes con un rendimiento promedio 
de 28 ton por hectárea por ciclo productivo. Se considera que la mayor cantidad de cortes es debido a que no se necesita dejar de regar para las actividades de maquinado. Después de cada corte se realizan las actividades de rastrillo, empaque y levante de pacas. La comercialización de la muestra se enfoca al mercado local.

\subsection{Definición de puntos críticos}

A través de la realización de entrevistas a los agricultores de los 12 puntos de muestreo, se obtuvieron 17 menciones de puntos críticos, donde los factores más mencionados fueron las plagas, seguidas del precio de insumos y la escasez de agua en cantidad y tiempo. La Figura 4 presenta un diagrama de Pareto que contiene los puntos críticos del sistema según los usuarios.

La mayoría de los usuarios considera las plagas el punto más crítico para la producción, ya que este conlleva a un producto de menor calidad y disminuye los rendimientos. Sin embargo, todos los factores están relacionados con el incremento en la utilización de insumos.

Figura 4. Diagrama de Pareto de los puntos críticos de producción de alfalfa según muestra.

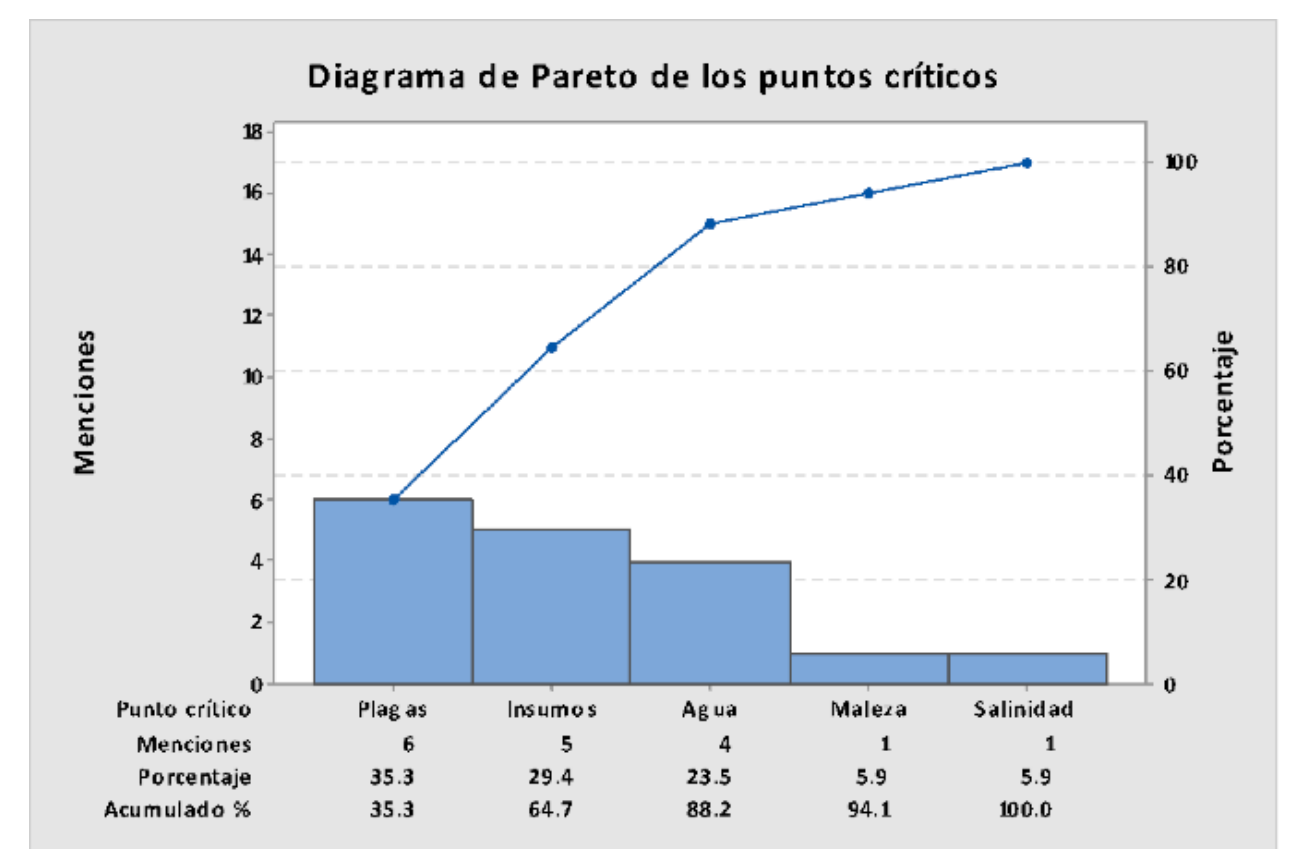


Análisis de sistemas de riego por gravedad y goteo subsuperficial basada en una encuesta de muestra de conveniencia en el valle de Mexicali B. Bringas-Burgos, I. Mendoza-Muñoz, C. Navarro-González, A. González-Ángeles y G. Jacobo-Galicia

- VÍNCULOS-ESPE (2020) VOL.5, No.3: 13 - 32

\subsection{Selección de indicadores}

Posteriormente, en base a la opinión de los productores se elaboró un diagrama de Ishikawa (ver Figura 5) para determinar las posibles causas de los puntos críticos y hacer una estimación de la relación entre dichos puntos, tomando en cuenta a los diversos actores dentro del proceso productivo (usuarios, administradores, funcionarios, investigadores en el uso del agua, etc.). En la Figura 5 se observa que la mayoría de los elementos mostrados se correlacionan entre sí, donde culminan

en la baja producción, el alto precio en insumos y la ineficiencia en el uso del agua. Lo anterior nos permite identificar los pilares más frágiles que sostienen la sustentabilidad de la producción de alfalfa, siendo referencia para proponer los indicadores empleados para el estudio, tomando en cuenta la viabilidad en la toma de mediciones como del alcance descriptivo del indicador, los cuales se presentan finalmente en la Tabla 3.

Figura 5. Diagrama de Ishikawa para determinar puntos críticos en la producción de alfalfa.

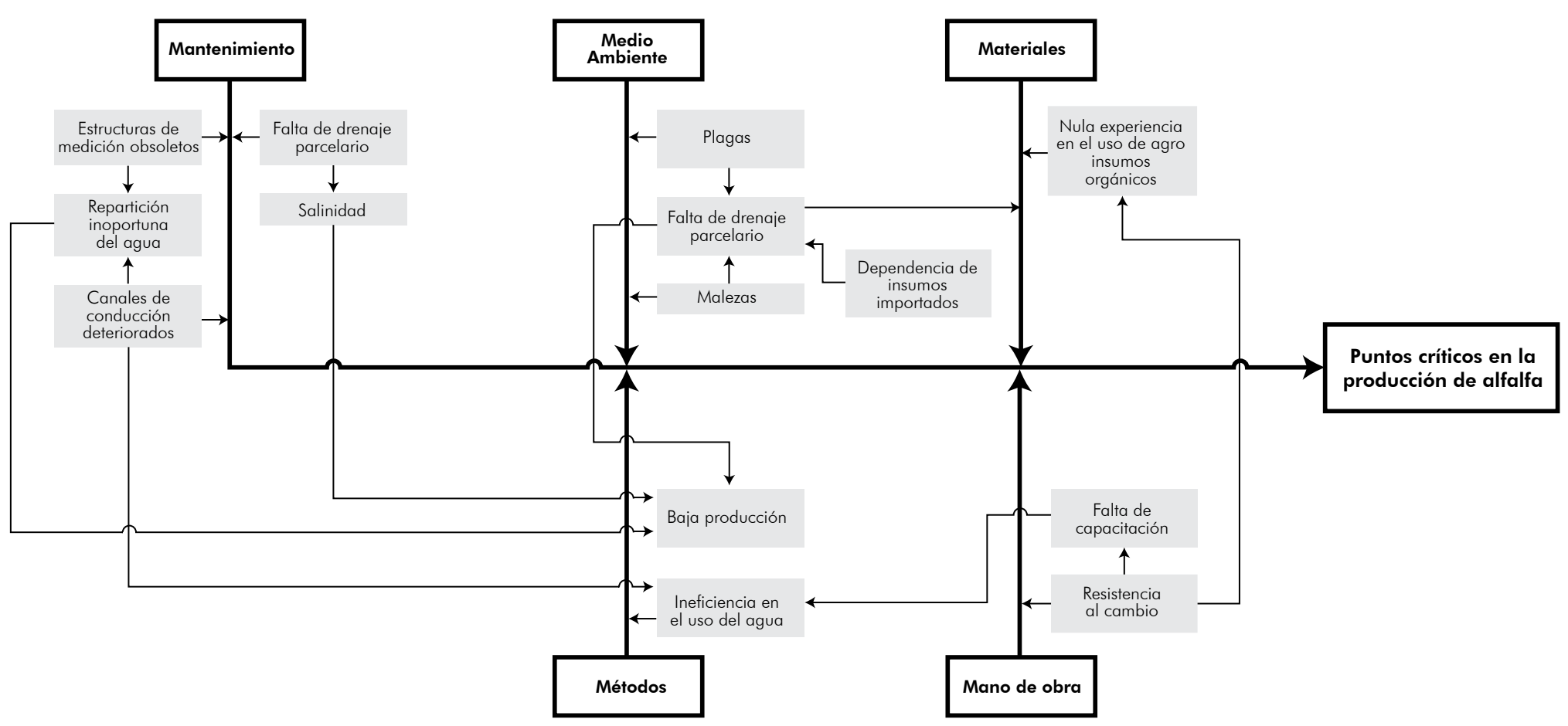


Tabla 3. Lista de indicadores propuestos a nivel parcela.

\begin{tabular}{|c|c|c|c|c|c|c|}
\hline Atributo & Criterio & Indicador & $\begin{array}{l}\text { Método } \\
\text { de medición }\end{array}$ & Umbral & $\begin{array}{l}\text { Área de } \\
\text { evaluación }\end{array}$ & Unidad \\
\hline Productividad & Eficiencia & Costo beneficio & $\begin{array}{c}\text { Cuestionario, } \\
\text { Análisis financiero }\end{array}$ & $\begin{array}{c}\text { Comparación } \\
\text { pareada }\end{array}$ & Económica & $\begin{array}{c}\text { Coeficiente } \\
\text { costo beneficio }\end{array}$ \\
\hline Productividad & Eficiencia & $\begin{array}{l}\text { Intensidad del } \\
\text { uso del agua }\end{array}$ & Cuestionario & $\begin{array}{c}\text { Comparación } \\
\text { pareada }\end{array}$ & Ambiental & $\begin{array}{l}\text { I/s por } 24 \mathrm{~h} \\
\text { porton }\end{array}$ \\
\hline Productividad & Eficiencia & $\begin{array}{c}\text { Intensidad del uso } \\
\text { de energéticos }\end{array}$ & $\begin{array}{c}\text { Cuestionario, } \\
\text { Análisis energético }\end{array}$ & $\begin{array}{c}\text { Comparación } \\
\text { pareada }\end{array}$ & Ambiental & $\begin{array}{l}\text { I de diésel } \\
\text { porton }\end{array}$ \\
\hline Adaptabilidad & $\begin{array}{c}\text { Adaptación a } \\
\text { propuestas } \\
\text { tecnológicas }\end{array}$ & $\begin{array}{c}\text { Agricultores que } \\
\text { reciben } \\
\text { capacitación }\end{array}$ & Cuestionario & 0 a $100 \%$ & Social & $\%$ de la muestra \\
\hline $\begin{array}{l}\text { Resiliencia y } \\
\text { estabilidad }\end{array}$ & $\begin{array}{c}\text { Conservación } \\
\text { de recursos }\end{array}$ & $\begin{array}{l}\text { Calidad } \\
\text { del agua }\end{array}$ & Muestreo & $\begin{array}{l}\text { Intervalo de } \\
\text { laboratorio }\end{array}$ & Ambiental & $\begin{array}{c}\text { Intervalos de clases de agua de } \\
\text { riego }\end{array}$ \\
\hline $\begin{array}{l}\text { Resiliencia y } \\
\text { estabilidad }\end{array}$ & $\begin{array}{c}\text { Conservación } \\
\text { de recursos }\end{array}$ & $\begin{array}{l}\text { Salinidad } \\
\text { del suelo }\end{array}$ & Muestreo & $\begin{array}{l}\text { Intervalo de } \\
\text { laboratorio }\end{array}$ & Ambiental & $\begin{array}{l}\text { Intervalo de valoración de } \\
\text { salinidad del suelo }\end{array}$ \\
\hline $\begin{array}{l}\text { Resiliencia y } \\
\text { estabilidad }\end{array}$ & $\begin{array}{l}\text { Estrés } \\
\text { ambiental }\end{array}$ & $\begin{array}{l}\text { Presencia de } \\
\text { pulgón }\end{array}$ & Muestreo & $\begin{array}{c}\text { Comparación } \\
\text { pareada }\end{array}$ & Ambiental & $\begin{array}{l}\text { Número de plagas por muestreo } \\
\text { de } 100 \text { golpes de red }\end{array}$ \\
\hline $\begin{array}{l}\text { Resiliencia y } \\
\text { estabilidad }\end{array}$ & $\begin{array}{c}\text { Estrés } \\
\text { ambiental }\end{array}$ & $\begin{array}{l}\text { Presencia de } \\
\text { malezas }\end{array}$ & Muestreo & $\begin{array}{l}\text { Intervalo de } \\
\text { laboratorio }\end{array}$ & Ambiental & Intervalo de muestreo \\
\hline Autogestión & $\begin{array}{c}\text { Dependencia } \\
\text { de insumos } \\
\text { externos }\end{array}$ & $\begin{array}{l}\text { Utilización de } \\
\text { insumos de } \\
\text { producción local }\end{array}$ & Cuestionario & 0 a $100 \%$ & Económica & $\%$ de la muestra \\
\hline Equidad & $\begin{array}{c}\text { Equidad en la } \\
\text { distribución de } \\
\text { recursos }\end{array}$ & $\begin{array}{c}\text { Percepción de la } \\
\text { repartición del } \\
\text { agua }\end{array}$ & Cuestionario & 0 a $100 \%$ & Social & $\%$ de la muestra \\
\hline
\end{tabular}

Aun cuando existen indicadores que describirían con mayor exactitud la relación del sistema de riego (profundidad y capilaridad del suelo, presencia de sustancias tóxicas en el agua, calidad de vida de los usuarios, entre otros), estos requieren el monitoreo y análisis de datos por un periodo considerable, siendo una tarea complicada. Por lo que, los indicadores propuestos para el estudio son tomados como una primera aproximación para abordar la evaluación de los sistemas productivos de alfalfa en el Valle de Mexicali en el contexto sustentable a nivel productivo, en función del sistema utilizado. 
Los estándares de calidad que definen la "calificación" o el estado de sustentabilidad para cada uno de los indicadores propuestos son: coeficientes o comparación direcła entre ambos sistemas (comparación pareada) en los aspectos económicos y ambientales y; percepciones de los usuarios (positivas o negativas) con valoración como un porcentaje de la muestra para los aspectos dentro del área social.

\subsection{Medición de indicadores}

Se muestran en la Tabla 4 los resultados de la medición de los indicadores seleccionados para el estudio. Estos resultados comprenden los datos obtenidos del sistema productivo en función del sistema de riego utilizado.

Tabla 4. Resultados obtenidos de la medición de indicadores.

\begin{tabular}{|c|c|c|c|}
\hline \multirow{2}{*}{ Indicador } & \multicolumn{2}{|c|}{ Sistema de Riego } & \multirow{2}{*}{ Comentarios } \\
\hline & Por gravedad & Por goteo & \\
\hline $\begin{array}{l}\text { Relación costo } \\
\text { beneficio }\end{array}$ & $1.19 \mathrm{C} / \mathrm{B}$ & $1.25 \mathrm{C} / \mathrm{B}$ & $\begin{array}{l}\text { Coeficiente de costo } \\
\text { beneficio con un } 10 \% \text { de tasa } \\
\text { de descuento a } 5 \text { años. }\end{array}$ \\
\hline $\begin{array}{l}\text { Intensidad en el uso del } \\
\text { agua }\end{array}$ & $1,116,288$ litros por ton & 416,571 litros por ton & $\begin{array}{l}\text { Litros de agua utilizados para producir una } \\
\text { tonelada de alfalfa. Promedio calculado a un año. }\end{array}$ \\
\hline \multirow{2}{*}{$\begin{array}{l}\text { Intensidad en el uso de } \\
\text { energéticos }\end{array}$} & 19.54 litros por ton & 17.11 litros por ton & $\begin{array}{c}\text { Litros de diésel utilizados para producir una } \\
\text { tonelada de alfalfa. }\end{array}$ \\
\hline & $58.44 \mathrm{~kg}$ por litro & 51.15 kg por litro & $\begin{array}{l}\text { Kilos de alfalfa producidos } \\
\text { por litro de diésel. }\end{array}$ \\
\hline $\begin{array}{l}\text { Adaptación a } \\
\text { propuestas } \\
\text { tecnológicas }\end{array}$ & $54 \%$ & $100 \%$ & $\begin{array}{l}\text { Porcentaje de la muestra que recibe por lo menos } \\
\text { una capacitación. }\end{array}$ \\
\hline \multirow{3}{*}{ Calidad del agua } & $\begin{array}{l}\text { Problema de salinidad } \\
\text { potencial medio. }\end{array}$ & $\begin{array}{l}\text { Problema de salinidad } \\
\text { potencial alto. }\end{array}$ & \multirow{3}{*}{ Riego por goteo = agua de pozo. } \\
\hline & $\begin{array}{c}\text { Problema de } \\
\text { sodicidad bajo. }\end{array}$ & $\begin{array}{c}\text { Problema de } \\
\text { sodicidad potencial alto. }\end{array}$ & \\
\hline & $\begin{array}{c}\text { Agua apta para riego de } \\
\text { cultivos tolerantes a } \\
\text { sales. }\end{array}$ & Agua no apta para riego. & \\
\hline Calidad del suelo & Ligeramente salino. & Ligeramente salino. & Muestreo de $0-30 \mathrm{~cm}$ \\
\hline \multirow{2}{*}{ Presencia de pulgón } & Muestra $1=296$ & Muestra $1=37$ & \multirow{2}{*}{$\begin{array}{l}\text { Cantidad de pulgones encontrados en muestras } \\
\text { transversales. }\end{array}$} \\
\hline & Muestra $2=1014$ & Muestra $2=243$ & \\
\hline Presencia de malezas & Menos de 4 por $\mathrm{m}^{2}$ & 0 por $\mathrm{m}^{2}$ & $\begin{array}{l}\text { Numero de malezas } \\
\text { por metro cuadrado. }\end{array}$ \\
\hline $\begin{array}{l}\text { Dependencia de } \\
\text { insumos externos }\end{array}$ & $91 \%$ & $100 \%$ & $\begin{array}{c}\text { Porcentaje de insumos } \\
\text { importados sobre insumos producidos en la } \\
\text { localidad. }\end{array}$ \\
\hline $\begin{array}{c}\text { Equidad en la } \\
\text { distribución de agua }\end{array}$ & \multicolumn{2}{|c|}{$55 \%=$ Sí; $45 \%=$ No. } & $\begin{array}{c}\text { Percepción de la igualdad en la repartición de } \\
\text { agua. }\end{array}$ \\
\hline
\end{tabular}


Adicionalmente, se encuestó a los usuarios del sistema de referencia sobre su opinión o prospectiva acerca del uso del sistema de riego por goteo subsuperficial en el cultivo de alfalfa, en donde un $73 \%$ no tienen considerado el utilizar este sistema alternativo por distintas razones, destacando la inversión inicial y la mala reputación que adquirió este sistema debido a proyectos mal diseñados en el Valle de Mexicali alrededor del año 2007, los cuales terminaron por ser removidos de los predios.
Una vez integrados los indicadores, se elaboró la evaluación de sustentabilidad representada en la gráfica radial de la Figura 6, con el fin de presentar visualmente la diferencia entre los sistemas e identificar las áreas más débiles o "insostenibles". Los indicadores elevados a la menos 1 representan indicadores que entre menos sea su valor cuantitativo están más cerca de un perfil sustentable.

Figura 6. Gráfica de evaluación de sustentabilidad.

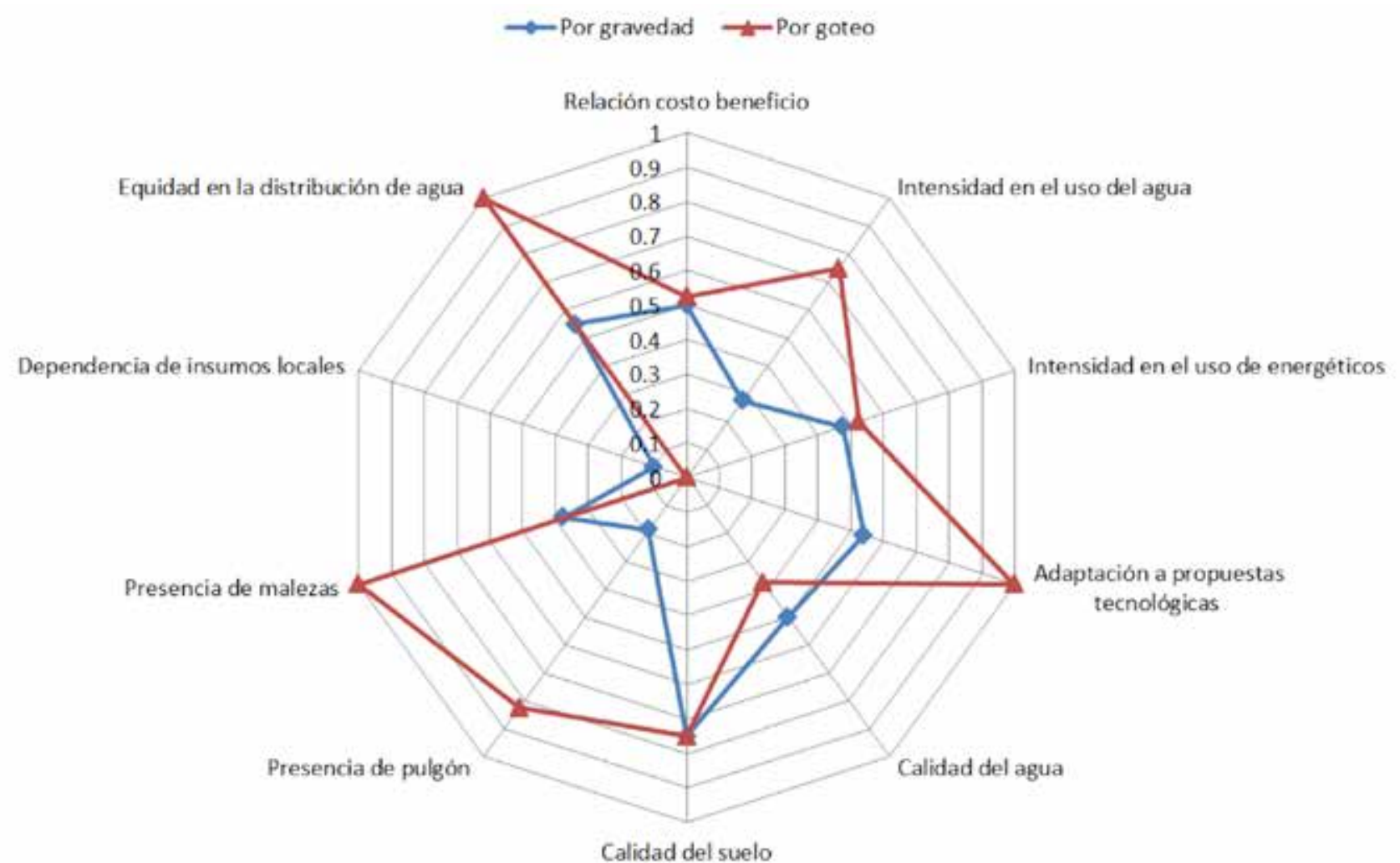

Calidad del suelo 
Análisis de sistemas de riego por gravedad y goteo subsuperficial basada en una encuesta de muestra de conveniencia en el valle de Mexicali B. Bringas-Burgos, I. Mendoza-Muñoz, C. Navarro-González, A. González-Ángeles y G. Jacobo-Galicia

- VÍNCULOS-ESPE (2020) VOL.5, No.3: 13 - 32

\section{DISCUSIÓN}

En este estudio, la comparación del sistema de riego por gravedad con el riego por goteo subsuperficial para la producción de la alfalfa en el Valle de Mexicali mostró que el sistema alternativo expone un escenario favorecedor en términos sustentables. El sistema de riego por goteo presenta evidencia consistente en 8 de los 10 indicadores analizados, apuntando a que este sistema es superior al sistema de referencia. En términos de sustentabilidad, el sistema alternativo mostró superioridad en los atributos de productividad, equidad, resiliencia y adaptabilidad; mientras que el sistema de riego por gravedad presentó predominio en autogestión, aunque ambos sistemas obtuvieron valores muy bajos en este atributo.

Considerando el marco de evaluación social, se encontró una opinión dividida en cuanto a la equidad en la repartición de los recursos. La explicación tentativa para este resultado apunta a que algunos usuarios no obtienen agua en el tiempo acordado, los cuales sugieren que es debido a la presencia de nexos cercanos entre los administradores del recurso con otros usuarios, favoreciendo a éstos últimos y, por ende, afectando el suministro de agua. Adicionalmente, se detectó una baja capacitación de los usuarios sobre el sistema productivo, los cuales llevan a cabo sus actividades con métodos que han sido adquiridos por sus predecesores. Este enfoque de producción ha permanecido como un problema al causar un desequilibrio en los recursos naturales (Astier et al., 2012; Valdez-Vazquez et al., 2017).

Dentro del área de evaluación económica, el análisis costo beneficio bajo distintas tasas de descuento muestran que el sistema de riego por goteo será superior. Sin embargo, estos datos deben ser interpretados con cautela puesto que se debe considerar la alta inversión inicial, así como el riesgo latente que existe si no se cuenta con un adecuado desarrollo y seguimiento (capacitación, manejo, etc.) del proyecto. Además, se debe observar el origen de los recursos financieros, ya que entre mayor sea el costo de oportunidad, el sistema de riego por gravedad resulta ser posiblemente, la opción más viable y conservadora en términos económicos. Por otro lado, después de un periodo de 6 años de operación con el sistema de riego por goteo, el nuevo ciclo de producción requerirá la inversión del 15\% aproximadamente (cinta de goteo e instalación) en comparación con la inversión inicial, por lo que un adecuado mantenimiento del resto de los componentes del equipo asegurará ganancias aún mayores a largo plazo. Adicionalmente, se detectó dentro del plano económico una alta dependencia de insumos importados de Estados Unidos, ocasionando la fragilidad económica en ambos sistemas productivos considerando la paridad del peso contra el dólar americano.

En lo que se refiere al área de evaluación ambiental, el esquema de producción tradicional utilizando el sistema riego por gravedad ha dado como resultado un aumento en la cantidad de plagas presentes como en la densidad de maleza en los cultivos de alfalfa, así como una creciente resistencia a los plaguicidas. Con respecto al sistema de riego por goteo, se observó una diferencia estadísticamente significativa en la presencia de pulgones, de aproximadamente un $87 \%$ menor para el primer muestreo y de un $76 \%$ para el segundo en contraste con el sistema de referencia. 
Asimismo, el sistema alternativo mostró una presencia de maleza casi nula. Este último resultado coincide con los hallazgos de otros estudios, en los que atribuyen que este sistema de riego minimiza el requerimiento de agua al reducir las pérdidas de aplicación (evaporación del suelo, etc.) y minimizando el crecimiento de malezas (Ayars et al., 2015; Eranki et al., 2017; Sinha et al., 2017). Por otro lado, el análisis del agua subterránea (agua de pozo) mostró niveles de salinidad muy altos para ser clasificada como recurso no apto para la agricultura. Los usuarios sugieren que esta problemática se intensificó poco después del terremoto de abril del 2010. En contraste, el agua superficial resultó de buena calidad a ligeramente salina. Cabe señalar que aun cuando no existe una relación directa entre la calidad del agua y el tipo de sistema de riego, no puede excluirse la condición de este recurso desde el enfoque sustentable. Un hallazgo inesperado fue que aun cuando el sistema de riego por gravedad utilizó agua de mejor calidad, ambos sistemas mostraron condiciones de suelo muy similares. Aunque una posible explicación para el resultado anterior es el alto uso de mejoradores de suelo, se sugiere llevar a cabo otros estudios que tomen en cuenta muestras con profundidades mayores de $30 \mathrm{~cm}$. En cuanto a la intensidad del uso de agua y energéticos (diésel), el sistema alternativo mostró una reducción del $63 \%$ y $9.3 \%$ por tonelada de alfalfa respectivamente, en contraste con el sistema de riego por gravedad.

Por otra parte, es conveniente mencionar que algunos de los indicadores utilizados en este estudio aparentan estar relacionados con la participación extranjera (en su mayoría de Estados Unidos), haciendo notar su presencia en el uso de insumos provenientes del país vecino, el paradigma productivo intensivo que ha sido implementado desde los principios de la agricultura en el Valle de Mexicali hasta el día de hoy, así como la renta de predios a precios elevados (siendo inaccesibles para agricultores locales), así como el control que poseen sobre la producción en otros cultivos como el algodón y trigo a través de comercializadoras, en donde los usuarios mencionaron como insatisfactoria la retribución económica que reciben por tales organizaciones. Este escenario podría ser un factor importante en cuanto a que ambos sistemas de riego mostraron niveles de autogestión bajos como se aprecia en la Figura 6, por lo que se sugiere un mayor estudio sobre la relación entre la sustentabilidad de estos sistemas de riego con respecto a la participación extranjera en el Valle de Mexicali.

\section{CONCLUSIÓN}

La presente investigación ha permitido evaluar los sistemas de riego por gravedad y por goteo subsuperficial para la producción de alfalfa en el Valle de Mexicali en donde finalmente, a través de las diversas dimensiones de sustentabilidad (social, económica y ambiental), los resultados sugieren que el sistema de riego por goteo es mayormente sustentable.

Al analizar los puntos críticos (plagas, insumos y agua) identificados en las encuestas de muestra de conveniencia, se hallaron 655 pulgones (plagas) promedio en las muestras transversales del sistema de riego por gravedad, en contraste con los 140 pulgones promedio en las muestras transversales 
del sistema de riego por goteo. Es importante señalar que todos los puntos estudiados utilizan un método de control de plagas (92\% químico), por lo que el sistema de riego por gravedad puede considerarse un factor significativo para la presencia de plaga. Con respecto a los insumos utilizados, se encuentra una total dependencia de insumos locales para el sistema de riego por goteo con respecto al sistema de riego por gravedad (91\%), lo que garantiza la continuidad de operación del primero. Finalmente, al estudiar los resultados obtenidos para el agua, se tiene: a) que el sistema de riego por gravedad consume 2.7 veces más que el sistema de riego por goteo, ofreciendo una mayor eficiencia de consumo de este recurso; b) la calidad del agua no puede ser comparable para evaluar la sustentabilidad de los sistemas de riego, ya que los puntos de obtención en ambos sistemas son diferentes (se recomienda considerar este punto en estudios posteriores), aunque se encontró que el agua de pozo no es apta para esta actividad y; c) se tiene problemas de percepción en la igualdad de repartición de agua en ambos sistemas, ya que el $45 \%$ de los encuestados no consideran que se tiene equidad en este punto. A pesar de mostrar notables beneficios el sistema de riego por gravedad (8 de 10 indicadores propuestos), los encuestados no consideran utilizar este sistema por los costos de inversión inicial y la percepción negativa de proyectos mal diseñados en la zona.
El estudio se vio limitado debido a que la metodología fue abordada desde un enfoque holístico, dando como consecuencia que los resultados obtenidos se enfocarán mayormente a un abordaje general de la problemática en el entorno. En contraste, al ser una evaluación cíclica, la profundización en aspectos críticos es un paso sucesivo para la resolución detallada de tales problemas. Finalmente, la investigación permitió identificar aspectos que merecen un análisis más detallado.

\section{AGRADECIMIENTOS}

Los autores agradecen al Consejo Nacional de Ciencia y Tecnología (CONACYT) en México, por otorgar la beca de posgrado a Brando Bringas-Burgos (CVU No. 616312), la cual permitió realizar este trabajo de investigación.

\section{REFERENCIAS}

Alvarado, A. A. (2007). El boom de las empresas extranjeras en el Valle de Mexicali: Efectos en las relaciones empresariales locales (19121930). Frontera Norte, 19(37), 113-142.

Astier, M., García-Barrios, L., Galván-Miyoshi, Y., González-Esquivel, C. E., \& Masera, O. R. (2012). Assessing the Sustainability of Small Farmer Natural Resource Management Systems. A Critical Analysis of the MESMIS Program (1995-2010). Ecology and Society, 17(3), art25. https://doi.org/10.5751/ES-04910-170325

Astier, M., Masera, O. R., \& Galván-Miyoshi, Y. (2008). Evaluacion de Sustentabilidad: Un Enque Dinamico y Multidimensional (Primera Ed). SEAE / CIGA / ECOSUR / CIECo / UNAM / GIRA / Mundiprensa 
/ Fundación Instituto de Agricultura Ecológica y Sustentable, España.

Ayars, J. E., Fulton, A., \& Taylor, B. (2015). Subsurface drip irrigation in California-Here to stay? Agricultural Water Management, 157(31), 39-47. https://doi.org/10.1016/i.agwat.2015.01.001

Broa-Rojas, E., Bahena-Delgado, G., Villareal-Manzo, L.-A., ValadezRamirez, M., \& Jaume-Hernández, M.-A. (2013). Uso eficiente del agua en la producción de maíces nativos de color en Xalostoc, Morelos. Ambiente y Desarrollo, 17(33), 99-111. https:// revistas.javeriana.edu.co/index.php/ambienteydesarrollo/article/ view/7045

Chávez, C., Fuentes, C., \& Ventura, E. (2010). Water Use Efficiency in Furrow Irrigation with Application of Gypsum and Polyacrylamide. Terra Latinoamericana, 28(3), 231-238.

CONAGUA. (2012). Programa Hídrico Regional Visión 2030. Región Hidrológico Administrativa IX Golfo Norte.

Eranki, P. L., El-Shikha, D., Hunsaker, D. J., Bronson, K. F., \& Landis, A. E. (2017). A comparative life cycle assessment of flood and drip irrigation for guayule rubber production using experimental field data. Industrial Crops and Products, 99(1), 97-108. https://doi. org/10.1016/j.indcrop.2017.01.020

Martínez Camacho, P. (2010). Los sistemas de información geográfica como herramientas para el diagnóstico integral y el mejoramiento de la operación del distrito de riego 014 Río Colorado, B.C. y Son. [Colegio de Postgraduados]. http://hdl.handle.net/10521/216

Moreno Mena, J., \& López Limón, M. G. (2005). Desarrollo agrícola y uso de agroquímicos en el Valle de Mexicali. Estudios Fronterizos, 6(12), 119-153.

Neri-Ramírez, E., Rubiños-Panta, J. E., Palacios-Velez, O. L., OropezaMota, J. L., Flores-Magdaleno, H., \& Ocampo-Fletes, I. (2013).
Evaluación de la sustentabilidad del acuífero Cuatitlán-Pachuca mediante el uso de la metodología MESMIS. Revista Chapingo Serie Ciencias Forestales y Del Ambiente, 19(2), 273-285. https://doi. org/10.5154/r.rchscfa.2011.11.086

OEIDRUS BC. (n.d.). SEHA-BC Series Históricas Agrícolas. http://www. oeidrus-bc.gob.mx/oeidrus_bca/

Rupérez-Moreno, C., Senent-Aparicio, J., Martinez-Vicente, D., GarcíaAróstegui, J. L., Calvo-Rubio, F. C., \& Pérez-Sánchez, J. (2017). Sustainability of irrigated agriculture with overexploited aquifers: The case of Segura basin (SE, Spain). Agricultural Water Management, 182(1), 67-76. https://doi.org/10.1016/i.agwat.2016.12.008

Singh, A. (2016). Evaluating the effect of different management policies on the long-term sustainability of irrigated agriculture. Land Use Policy, 54(1), 499-507. https://doi.org/10.1016/i. landusepol.2016.03.012

Sinha, I., Buttar, G. S., \& Brar, A. S. (2017). Drip irrigation and fertigation improve economics, water and energy productivity of spring sunflower ( Helianthus annuus L.) in Indian Punjab. Agricultural Water Management, 185(1), 58-64. https://doi.org/10.1016/i. agwat.2017.02.008

Valdez-Vazquez, I., del Rosario Sánchez Gastelum, C., \& Escalante, A E. (2017). Proposal for a sustainability evaluation framework for bioenergy production systems using the MESMIS methodology. Renewable and Sustainable Energy Reviews, 68(1), 360-369. https://doi.org/10.1016/i.rser.2016.09.136

Vélez Vargas, L. D. (2004). El paradigma científico de las ciencias agrarias: una reflexión. Revista Facultad Nacional de Agronomía, Medellín, 57(1), 2145-2160.

Vörösmarty, C. J. (2010). Global Threats to Human Water Security and River Biodiversity. Nature, 467(1), 555-561. 


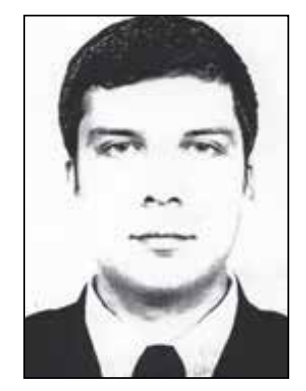

\section{B. BRINGAS BURGOS}

Actualmente estudiante del cuarto semestre del doctorado en Biociencias en la Universidad de Sonora. Es Ingeniero Industrial y Maestro en Ciencias por la Universidad Autónoma de Baja California.

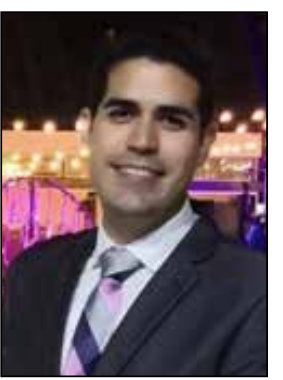

\section{MENDOZA-MUÑOZ}

- Ingeniero Mecánico, especialista en materiales, fabricación y diseño, con Maestría y Doctorado en Ciencias, todos ellos de la Universidad Autónoma de Baja California (UABC). Actualmente, es profesor e investigador a tiempo completo en la UABC. Es líder del grupo académico y de investigación "Manufactura y Salud Ocupacional". Ha publicado manuscritos en revistas, libros y capítulos de libros y ha participado como crítico invitado en revistas internacionales. Sus intereses de investigación son las áreas de biomecánica, ergonomía, materiales, fabricación y diseño.

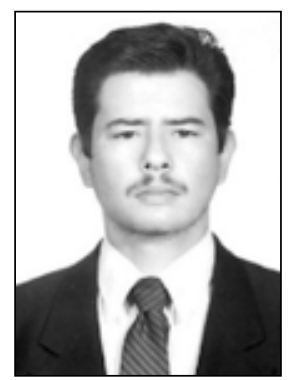

\section{NAVARRO-GONZÁLEZ}

Actualmente miembro de la Universidad Autónoma de Baja California como profesor investigador de la carrera de Ingeniero Industrial. Con varios artículos relacionados con "Manufactura Esbelta", "Seis Sigma" y "Optimización de Procesos", "Salud Ocupacional y Ergonomía". Es Ingeniero Industrial por la Universidad Panamericana, con Maestría en Ingeniería en Procesos Industriales y Doctorado en Ingeniería por la UABC. Con líneas de trabajo como y desarrollo de líneas de investigación orientadas a Ergonomía y Salud Ocupacional tales como "Antropometría Digital" "Maniquíes Antropométricos" "Uso de sensores biométricos". Actualmente es miembro del Cuerpo Académico de "Manufactura y Salud Ocupacional".

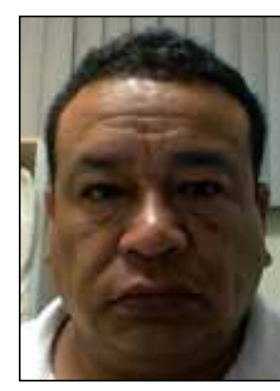

\section{A. GONZALEZ-ANGELES}

Recibió el grado de Ingeniero Mecánico Industrial en 1995, su Maestría en Ciencias en Tratamientos Térmicos y Metalografía en 1997, todos ellos del Instituto Tecnológico de Morelia México; su Doctorado en Ciencias en Ingeniería Metalúrgica y Cerámica en el Centro de Estudios Avanzados e Investigaciones del IPN, CINVESTAV- Campus Saltillo, México en 2004. Sus áreas de interés de investigación son: tratamientos térmicos, termoquímicos (cementación de empaques) y metalografía. Materiales cerámicos magnéticos nanoestructurados, nanocompuestos magnéticos y nanopartículas procesadas por aleación mecánica. Desarrollo y estudio de compuestos de fibra natural y compuestos de fibra de carbono.

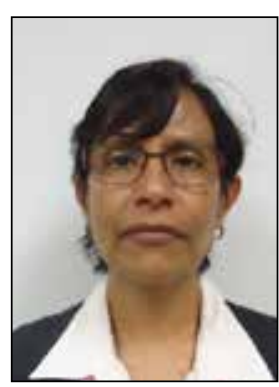

\section{G. JACOBO-GALICIA}

- Obtuvo el grado de Ingeniero en Cibernética Electrónica tiene una Maestría en Ciencias en Sistemas de Calidad y Productividad de Instituto Tecnológico de Estudios Superiores de Monterrey, campus Monterrey y Doctorado en Ciencias por la Universidad Autónoma de Ciudad Juárez, campus Ciudad Juárez Chihuahua. Ha trabajado como ingeniero de procesos en la industria electrónica durante más de 10 años y desde el 2006 se desempeña como profesor-investigador de tiempo completo en la Facultad de Ingeniería de la Universidad Autónoma de Baja California. 